\title{
NMR-based metabonomic studies reveal changes in the biochemical profile of plasma and urine from pigs fed high-fibre rye bread
}

\author{
Hanne C. Bertram ${ }^{1}$, Knud E. Bach Knudsen ${ }^{2}$, Anja Serena ${ }^{2}$, Anders Malmendal ${ }^{3}$, Niels Chr. Nielsen ${ }^{3}$, \\ Xavier C. Fretté ${ }^{1}$ and Henrik J. Andersen ${ }^{1}$ \\ ${ }^{1}$ Department of Food Science, Danish Institute of Agricultural Sciences, Box 50, DK-8830 Tjele, Denmark \\ ${ }^{2}$ Department of Animal Health, Welfare and Nutrition, Danish Institute of Agricultural Sciences, Box 50, DK-8830 Tjele, Denmark \\ ${ }^{3}$ Department of Chemistry and Interdisciplinary Nanoscience Center (iNANO), University of Aarhus, Langelandsgade 140, \\ DK-8000 Aarhus C, Denmark
}

(Received 9 August 2005 - Revised 13 January 2006 - Accepted 29 January 2006)

\begin{abstract}
This study presents an NMR-based metabonomic approach to elucidate the overall endogenous biochemical effects of a wholegrain diet. Two diets with similar levels of dietary fibre and macronutrients, but with contrasting levels of wholegrain ingredients, were prepared from wholegrain rye (wholegrain diet (WGD)) and non-wholegrain wheat (non-wholegrain diet (NWD)) and fed to four pigs in a crossover design. Plasma samples were collected after $7 \mathrm{~d}$ on each diet, and ${ }^{1} \mathrm{H}$ NMR spectra were acquired on these. Partial least squares regression discriminant analysis (PLSDA) on spectra obtained for plasma samples revealed that the spectral region at 3.25 parts per million dominates the differentiation between the two diets, as the WGD is associated with higher spectral intensity in this region. Spiking experiments and LC-MS analyses of the plasma verified that this spectral difference could be ascribed to a significantly higher content of betaine in WGD plasma samples compared with NWD samples. In an identical study with the same diets, urine samples were collected, and ${ }^{1} \mathrm{H}$ NMR spectra were acquired on these. PLS-DA on spectra obtained for urine samples revealed changes in the intensities of spectral regions, which could be ascribed to differences in the content of betaine and creatine/creatinine between the two diets, and LC-MS analyses verified a significantly lower content of creatinine in WGD urine samples compared with NWD urine samples. In conclusion, using an explorative approach, the present studies disclosed biochemical effects of a wholegrain diet on plasma betaine content and excretion of betaine and creatinine.
\end{abstract}

NMR: Betaine: Creatinine: Wholegrain: Metabolomics

Epidemiological studies have revealed a connection between the consumption of diets rich in wholegrain cereals and decreased incidences of several degenerative 'Western' diseases, and there is strong evidence that wholegrain foods protect against CVD and certain cancers (Anderson et al. 2000; Levi et al. 2000; Slavin et al. 2001; Truswell, 2002), and increasing data are in support of a protective effect against type II diabetes (Fung et al. 2002; McKeown et al. 2002; Pereira et al. 2002). The food factor responsible for the preventive effects of wholegrain is still unknown. However, wholegrain cereals are rich in dietary fibre, vitamins and minerals, and bioactive compounds such as phytochemicals and micronutrients with potential effects on metabolism and cancer development (Slavin et al. 1999).

NMR is a non-destructive and non-selective technique that can be applied on a variety of materials. Since the first demonstration of the use of ${ }^{1} \mathrm{H}$ NMR spectroscopy on whole blood and blood plasma (Nicholson et al. 1983), ${ }^{1} \mathrm{H}$ NMR spectroscopy of biofluids has proven an excellent tool for investigation of biochemical changes associated with drug toxicity in animal models (Holmes et al. 1998; Lenz et al. 2000;
Waters et al. 2001; Beckwith-Hall et al. 2002; Keun et al. 2002; Beckonert et al. 2003; Coen et al. 2003; Ebbels et al. 2003). Promisingly, the technique has recently also been applied to study the biochemical effects of the bioactive compound epicatechin in a rat model, which allowed a demonstration of the overall endogenous metabolic effects of epicatechin consumption (Solanky et al. 2003a). Moreover, use of ${ }^{1} \mathrm{H}$ NMR spectroscopy on biofluids to screen the biochemical effects of dietary soya isoflavones in man has also been reported (Solanky et al. 2003b). Accordingly, ${ }^{1} \mathrm{H}$ NMR spectroscopy of biofluids can be considered an emerging and promising science with a level of information that spans the traditional approach for elucidating the biochemical response to a factor that can be ascribed to the fact that the method enables an entire endogenous metabolic profiling, i.e. a metabolic fingerprinting. In the present study, the use of high-resolution ${ }^{1} \mathrm{H}$ NMR spectroscopy was for the first time introduced for elucidating the biochemical effects of rye- and wheatbased diets using the pig as a model for human subjects. The study was carried out in two series of experiments with catheterized pigs, and ${ }^{1} \mathrm{H}$ NMR spectroscopy was performed 
on plasma samples drawn from the hepatic portal vein and the mesenteric artery as well as on urine samples.

\section{Materials and methods}

\section{Breads and diets}

The diets were made of wheat soft and crisp bread or rye soft and crisp bread, and are referred to as non-wholegrain diet (NWD) and wholegrain diet (WGD). Wheat and rye soft breads were produced at Nordmills (Nordmills, Cerealia AB, Malmo, Sweden) and wheat and rye crisp bread were produced at Wasa Bread (Wasa Bread AB, Sweden). The rye crisp bread contained wholegrain rye flour, rye bran (Wasa $\mathrm{T} 2$, Sweden), fat and salt as the main ingredients and the corresponding wheat crisp bread white wheat flour, purified wheat fibre essentially as cellulose (Vitacel WF 600; Rettenmair and Söhne, Holzmühle, Germany), sugar (sucrose), salt and dry malt. The soft rye bread contained white wheat flour, rye bran (B3-fin; Nordmills), baker's yeast, fat, salt and sugar and the corresponding soft wheat bread white wheat flour, vitacel, baker's yeast, fat, salt and sugar. Immediately after production, the soft bread was frozen at $-20^{\circ} \mathrm{C}$ until consumption, while crisp bread was stored dry. The diets prepared from soft and crisp bread were fortified with vitamins and minerals and provided approximately 19, 15 and $66 \%$ energy from fat, protein and carbohydrates, respectively (see Table 1 for diet ingredients and composition). Compared with diets for optimal growth of pigs at the present physiological state, the diets provided approximately $45 \%$ of the recommended concentration of lysine (first limited amino acid) but approximately $260 \%$ of the concentration of lysine for maintenance.

Table 1. Ingredients and chemical composition of the experimental diets (units/kg DM)*

\begin{tabular}{|c|c|c|}
\hline & NWD & WGD \\
\hline \multicolumn{3}{|l|}{ Ingredients } \\
\hline Wheat crisp bread (g) & 602 & \\
\hline Wheat soft bread (g) & 370 & \\
\hline Rye crisp bread (g) & & 593 \\
\hline Rye soft bread (g) & & 379 \\
\hline Vitamins/minerals (g) & 28 & 28 \\
\hline \multicolumn{3}{|l|}{ Chemical composition } \\
\hline Ash (g) & 33 & 56 \\
\hline Protein $(\mathrm{N} \times 6.25)(\mathrm{g})$ & 119 & 127 \\
\hline Fat $(g)$ & 68 & 73 \\
\hline Total carbohydrates $(\mathrm{g})$ & 777 & 717 \\
\hline Sugars $(g)$ & 24 & 40 \\
\hline Fructans $(\mathrm{g})$ & 4 & 18 \\
\hline Starch $(g)$ & 529 & 455 \\
\hline Total NSP and soluble NSP (g) & 220 and 23 & 203 and 55 \\
\hline Klason lignin $(g)$ & 10 & 32 \\
\hline Dietary fibre (NSP + lignin) (g) & 230 & 235 \\
\hline Total lignans (mg) & $3 \cdot 1$ & $35 \cdot 2$ \\
\hline Alkylresorcinols (mg) & 0 & $1 \cdot 2$ \\
\hline Betaine $(\mathrm{g})$ & 0.96 & 1.92 \\
\hline
\end{tabular}

NWD, non-wholegrain diet; WGD, wholegrain diet.

* The mineral and vitamin mixture provided the following (mg/kg diet): $\mathrm{Ca}_{2}\left(\mathrm{PO}_{4}\right)_{3}$, $14000, \mathrm{NaCl}, 4000 ; \mathrm{CaCO}_{3}, 8000 ; \mathrm{FeSO}_{4} \cdot 5 \mathrm{H}_{2} \mathrm{O}, 50 ; \mathrm{ZnO}, 80 ; \mathrm{MnO}, 27 ;$ CuSO ${ }_{4} \cdot 5 \mathrm{H}_{2} \mathrm{O}, 20 ; \mathrm{KI}, 0.2 ; \mathrm{Na}_{2} \mathrm{SeO}_{3}, 0.3$; retinyl acetate, 1.1; cholecalciferol, 0.01 ; dl- $\alpha$-tocopherol, 60; menadione, 2; riboflavin, 4; pantothenic acid, 11; cobalamin, 0.02; niacin, 22; biotin, 0.06 .

For details of diets and procedures, see this page.
Chemical analyses of diets were performed with classical methods as described in the papers by Bach Knudsen et al. (2003, 2005), Saarinen et al. (2001) and Linko et al. (2006).

\section{Experimental design and pigs}

The pigs used in both studies were from the Danish Institute of Agricultural Sciences swine herd, Foulum, Denmark.

Study 1. The study was a crossover design with four male castrated pigs (body weight 44.6 (SD 2.4) kg) fed the two diets for 1 week. Each pig was surgically fitted with two catheters, one in the portal vein $(1.2 \mathrm{~mm}$ i.d.) and the second in the mesenteric artery (1.0 $\mathrm{mm}$ i.d.), and with an ultrasonic blood flow probe (14 mm; Transonic System, Ithaca, NY, USA) around the portal vein. The pigs were given Streptocillin for up to $4 \mathrm{~d}$ after surgery. After $10 \mathrm{~d}$ post-surgery recovery, the pigs were gradually introduced to the two experimental diets and fed $1250 \mathrm{~g} \mathrm{DM} / \mathrm{d}$. The bread was cut into pieces, mixed 1:2.5 (w/w) with water and fed in equal amounts three times daily, at $07.00,15.00$ and 22.00 hours. For the present study we used portal and arterial blood samples taken $60 \mathrm{~min}$ after the morning feeding on day 7 . The blood was collected in heparinized plastic tubes and centrifuged $\left(3000 \mathrm{~g}\right.$ at $8^{\circ} \mathrm{C}$ for $10 \mathrm{~min}$ ) to separate the erythrocytes from plasma. The plasma was kept frozen at $-20^{\circ} \mathrm{C}$ until analysis.

Study 2. Six female pigs with an initial body weight of 38.7 (SD 2.7) $\mathrm{kg}$ were used for the study. The study was designed as a crossover experiment with washout periods before, between and after the dietary interventions. The pigs were fed 1 week with a semi-synthetic diet (Bach Knudsen et al. 2003) in periods 1, 3 and 5, whereas NWD and WGD were fed for 2 weeks in periods 2 and 4 . The breads were treated as in study 1 and fed in equal amounts twice daily (09.30 and 21.30 hours) together with a fixed amount of water (1:2.5). In the diet intervention periods (periods 2 and 4), the pigs were equipped with a urine bladder catheter for urine collection $(5.0 \mathrm{~mm}$ i.d.). All urine produced for $3 \mathrm{~d}$ was collected in benzoic acid via catheters. The total amount of urine collected for each pig was registered. No significant effect of diet on the amount of urine was found.

The animal experiments complied with the guidelines of the Danish Ministry of Justice with regard to animal experimentation and care of animals under study.

\section{NMR measurements}

The NMR measurements were performed at $300 \mathrm{~K}$ on a Bruker Avance 400 NMR spectrometer (Bruker BioSpin $\mathrm{GmbH}$, Rheinstetten, Germany), operating at a ${ }^{1} \mathrm{H}$ frequency of $400 \cdot 13 \mathrm{MHz}$, and equipped with a standard $5 \mathrm{~mm} \mathrm{HX}$ inverse probe.

Prior to the measurements, portal and arterial plasma samples ( $n$ 16) were thawed and $200 \mu$ l aliquots were mixed with $400 \mu 1 \mathrm{D}_{2} \mathrm{O}$. Sodium trimethylsilyl-[2,2,3,3- $\left.{ }^{2} \mathrm{H}_{4}\right]$-1-propionate was added as an internal chemical shift standard $(0.7 \mathrm{mg} / \mathrm{ml})$. ${ }^{1} \mathrm{H}$ NMR spectra of plasma samples were obtained using a Carr-Purcell-Meiboom-Gill delay added in order to attenuate broad signals from high molecular weight components. The total Carr-Purcell-Meiboom-Gill delay was $40 \mathrm{~ms}$ and the spin-echo delay was $200 \mu \mathrm{s}$. Urine samples ( $n$ 12) were thawed and $400 \mu$ l aliquots were mixed 
with $200 \mu \mathrm{l} \mathrm{D}_{2} \mathrm{O}$, and sodium trimethylsilyl-[2,2,3,3- $\left.{ }^{2} \mathrm{H}_{4}\right]-1$ propionate was added as an internal chemical shift standard $(0.7 \mathrm{mg} / \mathrm{ml})$. NMR measurements on plasma samples were also performed upon spiking of plasma samples with betaine (Sigma Chemical Co., St Louis, MO, USA), glycerophosphorylcholine (Sigma Chemical Co.), enterolactone (Labmaster Ltd, Turku, Finland), and alkylresorcinol C15:0 (KamalEldin et al. 2000), respectively. ${ }^{1} \mathrm{H}$ NMR spectra of urine samples were obtained using a single $90^{\circ}$ pulse experiment. Both on plasma and urine samples water suppression was achieved by irradiating the water peak during the relaxation delay of $2 \mathrm{~s}$. A total of 128 transients of $8 \mathrm{~K}$ data points spanning a spectral width of 24.03 parts per million (ppm) were collected. An exponential line-broadening function of $3 \mathrm{~Hz}$ was applied to the free induction decay prior to Fourier transform. All spectra were referenced to the sodium trimethylsilyl$\left[2,2,3,3-{ }^{2} \mathrm{H}_{4}\right]-1$-propionate signal at $0 \mathrm{ppm}$.

\section{Post-processing of NMR data}

The mean-normalized ${ }^{1} \mathrm{H}$ NMR spectra in the region 9.0$5.1 \mathrm{ppm}$ and the region $4 \cdot 6-0.5 \mathrm{ppm}$ were used for further data analysis. The spectra were segmented into regions of $0.04 \mathrm{ppm}$ width and the integral of each region was calculated. The reduced spectra consisting of 195 integrated regions were normalized to the whole spectrum to remove any concentration effects.

\section{LC-MS analyses}

Portal and arterial plasma samples, taken after $7 \mathrm{~d}$ of feeding with the two diets, from two pigs $(n-8)$ were analysed for betaine content, and all urine samples ( $n$ 12) were analysed for creatinine content using LC-MS. Original plasma sample $(200 \mu \mathrm{l})$ was pipetted and transferred into a Whatman vial (Chromtech $\mathrm{GmbH}$, Idstein, Germany); $500 \mu$ l acetonitrile (containing $0.1 \%$ formic acid) were added. After spontaneous flocculation of the proteins the plunger was inserted into the vial and pressed down, thus forcing the liquid upward through the membrane. Urine samples of $400 \mu$ l were prepared using the same procedure but without addition of acetonitrile to the samples. Analyses were performed on an Agilent (Agilent, Waldbronn, Germany) HPLC-diode-array detector-MS station equipped with an HPLC series 1100 comprising a model G1312A binary pump, a model G1379A micro vacuum degasser, a model G1327A thermostated autosampler, a model G1316A thermostated column compartment, a model G1315B diode-array detector and a model G2707DA LC/ MSD SL detector fitted with a model G1948A API-electrospray source. The station was controlled and the results were monitored with Agilent's ChemStation software (Rev. A.10.02).

Sample separations were carried out on a Varian (Lake Forest, CA, USA) OmniSpher C18 column $(100 \times 2.0 \mathrm{~mm}$ i.d., $3 \mu \mathrm{m}$ particle size) operated at a temperature of $35^{\circ} \mathrm{C}$ and with a $0.2 \mathrm{ml} / \mathrm{min}$ flow. The solvents used were: (A) aqueous $1 \%$ formic acid (formic acid of analytical-reagent grade; Riedel-de-Haën, Seelze, Germany; (B) $1 \%$ formic acid in HPLC-grade acetonitrile, using a gradient programme as follows: $0 \% \mathrm{~B}$ isocratic $(3 \mathrm{~min}), 0 \% \mathrm{~B}$ to $98 \% \mathrm{~B}(4 \mathrm{~min})$, $98 \% \mathrm{~B}$ isocratic $(6 \mathrm{~min})$. The injection volume was $1 \mu \mathrm{l}$.
UV spectra were recorded at 214 and $254 \mathrm{~nm}$ at a rate of $1.25 \mathrm{scans} / \mathrm{s}$.

MS spectra of samples were recorded simultaneously in SCAN (from $\mathrm{m} / \mathrm{z}, 50$ to 500) and SIM (ions with $\mathrm{m} / \mathrm{z} 114$ and 118) positive modes. The acquisition parameters were as follows: fragmentor $160 \mathrm{~V}$, gain $5 \mathrm{EMV}$, stepsize $0.10 \mathrm{~N}$ was used as drying gas at a flow of $111 / \mathrm{min}$ and as nebulizing gas at a pressure of $54 \mathrm{psig}$ and a temperature of $280^{\circ} \mathrm{C}$. A potential of $3000 \mathrm{~V}$ was used on the capillary.

Optimization of ionization and fragmentation parameters was carried out by running a fluoroimmunoassay with standard betaine and creatinine (Sigma Chemical Co).

\section{Statistics}

Statistical analysis of LC-MS data was performed by the Statistical Analysis Systems package version 8.2 (SAS Institute, Cary, NC, USA) using the MIXED procedure. A model including the fixed effect of diet (WGD $v$. NWD) and the random effect of animal was applied. Significant differences are indicated, and the $P$ value is given.

Multivariate data analysis was performed using the Unscrambler software version 8.0 (Camo, Oslo, Norway). Principal component analysis was applied to the centred data to explore any clustering behaviour of the samples, and partial least square regression discriminant analysis (PLS-DA) was performed to explore intrinsic biochemical dissimilarities between predefined sample classes (WGD diet $v$. NWD diet). During all regressions, Martens uncertainty test (Martens \& Dardenne, 1998) was used for jack-knifing, and all models were validated using full cross-validation.

\section{Results}

\section{Plasma samples}

Principal component analysis, which is an unsupervised method, was performed on the pre-processed ${ }^{1} \mathrm{H}$ NMR spectra, and the resulting plot of score $2 v$. score 3 for mean-centred data is shown in Fig. 1 with each spectrum represented by a

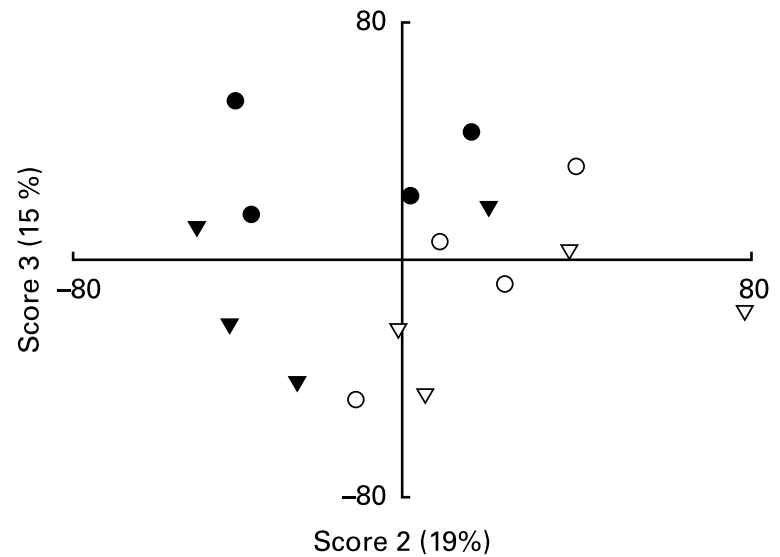

Fig. 1. Principal component analysis score plot showing the second and third principal components for non-wholegrain diet (NWD) and wholegrain diet (WGD) plasma sample groups. Plasma source (portal $v$. arterial) is also indicated. For details of procedures, see p. 956. - NWD, portal; O, WGD, portal; $\mathbf{\nabla}, \mathrm{NWD}$, arterial; $\nabla, \mathrm{WGD}$, arterial. 
single data point. A clear tendency to clustering according to diet is observed. PLS-DA, which is more focused on discriminating variation between pre-defined classes than the unsupervised principal component analysis approach, was performed on the ${ }^{1} \mathrm{H}$ NMR spectra to investigate the metabolic differences in plasma profile between WGD and NWD. The PLS-DA score plots of the first and second component show a clear separation of NWD and WGD plasma (Fig. 2(A)). The regions of the NMR spectrum that most strongly influence separation between WGD and NWD plasma are evident in the regression coefficients (Fig. 2(B)). A positive value indicates a relatively greater concentration of metabolite in WGD samples, and a negative value indicates a relatively lower concentration compared with NWD samples. The spectral region at $3.25 \mathrm{ppm}$ dominates the differentiation between the two diets. Jack-knifing reveals that three regions influence the discrimination between WGD and NWD samples significantly: $3.54,3.25$ and $1.28 \mathrm{ppm}$. Of these regions, the concentration of the compound at $3.54 \mathrm{ppm}$ is lower and the concentration of the compounds at 3.25 and $1.28 \mathrm{ppm}$ is higher in WGD plasma samples compared with NWD samples. The major regions showing differences between WGD and NWD plasma are summarized along with a tentative metabolite assignment in Table 2. The concentration of betaine was confirmed and quantified in plasma samples from two pigs after the intake of both rye- and wheat-based diet using LC-MS. A significantly higher content of betaine $(P=0.0012)$ was

(A)

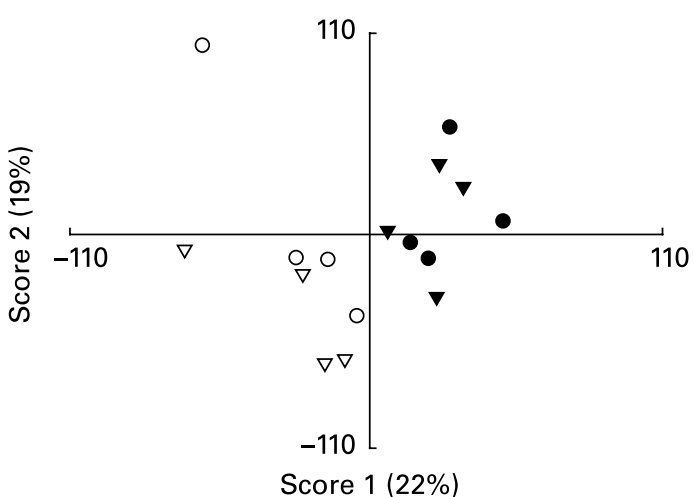

(B)

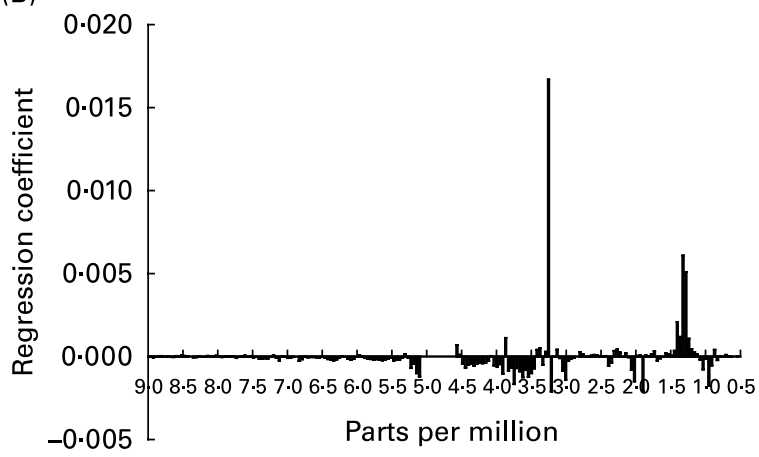

Fig. 2. (A), Partial least squares regression discriminant analysis (PLS-DA) score plot from analysis of NMR spectra obtained on non-wholegrain diet (NWD) and wholegrain diet (WGD) plasma samples. Plasma source (portal $v$. arterial) is also indicated. For details of procedures, see p. 956. $\bullet$, NWD, portal; $O$, WGD, portal; $\mathbf{\nabla}$, NWD, arterial; $\nabla$, WGD, arterial. (B), The regression coefficients of the PLS-DA shown in $(A)$. found in WGD plasma samples (5.53 (SE 0.46) $\mu \mathrm{g} / \mathrm{ml}$ ) compared with NWD plasma samples $(2 \cdot 10$ (SE 0.46) $\mu \mathrm{g} / \mathrm{ml})$.

Urine samples. Principal component analysis was performed on the pre-processed ${ }^{1} \mathrm{H}$ NMR spectra, and the resulting plot of score $1 v$. score 2 for mean-centred data is shown in Fig. 3. A clear tendency to clustering according to diet is observed along the first score. PLS-DA was performed on the ${ }^{1} \mathrm{H}$ NMR spectra to investigate the metabolic differences in urine profile between WGD and NWD. The PLS-DA score plots of the first and second component show a clear separation of NWD and WGD plasma (Fig. 4(A)). The regions of the NMR spectrum that most strongly influence separation between WGD and NWD plasma are evident in the regression coefficients (Fig. 4(B)). A positive value indicates a relatively higher concentration of metabolite in WGD samples, and a negative value indicates a relatively lower concentration compared with NWD samples. The spectral region at $3.25 \mathrm{ppm}$ dominates the differentiation between the two diets. The major regions showing differences between WGD and NWD urine are summarized along with a tentative metabolite assignment in Table 2. The concentration of creatinine in the urine samples was confirmed and quantified using LC-MS. A significantly higher content of creatinine $(P=0.03)$ was found in NWD urine samples (69.95 (SE 5.86) $\mu \mathrm{g} / \mathrm{ml}$ ) compared with WGD urine samples (48.71 (SE 5.86) $\mu \mathrm{g} / \mathrm{ml}$ ).

\section{Spiking experiments}

${ }^{1} \mathrm{H}$ NMR spectra were obtained on plasma after spiking with betaine, glycerophosphorylcholine, enterolactone and alkylresorcinol, respectively, and Table 3 summarizes the results. Betaine intensified two resonances at chemical shift values (3.25 and $3.92 \mathrm{ppm}$ ) identical to where resonances are evident in the plasma. In contrast, glycerophosphorylcholine showed three resonances at chemical shift values $(3.20,3.62$ and $4.15 \mathrm{ppm}$ ) where no resonances otherwise are clearly evident in the plasma. Finally, enterolactone resulted in an additional resonance at $3.56 \mathrm{ppm}$, while spiking with alkylresorcinol resulted in an enhancement in resonances at $0.9 \mathrm{ppm}$, $1.3 \mathrm{ppm}$, probably originating from the methyl and methylene protons in the alkyl part, and at $3.21 \mathrm{ppm}$, probably originating from protons in the resorcinol part.

\section{Discussion}

It is well established that a relationship exists between the consumption of wholegrain cereals and incidences of 'Western' diseases, CVD, certain types of cancers and diabetes (Anderson et al. 2000; Levi et al. 2000; Slavin et al. 2001; Fung et al. 2002; McKeown et al. 2002; Pereira et al. 2002; Truswell, 2002). However, the exact physiological mechanisms responsible for this relationship are still not understood. Pigs are recognized to be excellent models for human nutrition because of similarities with regard to digestive anatomy and many aspects of physiology (Miller \& Ullrey, 1987). The present study is the first to report the use of ${ }^{1} \mathrm{H}$ NMR spectroscopy on plasma and urine samples to study the metabolic differences between pigs fed a rye-based diet (WGD), rich in wholegrain and bran, and a wheat-based diet (NWD) with similar levels of dietary fibres, but with 
Table 2. Summary of the major differences between non-wholegrain diet (NWD) and wholegrain diet (WGD) samples*

\begin{tabular}{|c|c|c|c|}
\hline NMR spectral region (ppm) & Assignment† & Plasmał & Urine \\
\hline approximately $1.2-1.4$ & $\left(\mathrm{CH}_{2}\right)_{n}$ in fatty acids & $\uparrow$ & - \\
\hline 3.03 & $\mathrm{~N}-\mathrm{CH}_{3}$ in creatinine/creatine & - & $\downarrow$ \\
\hline $3 \cdot 25$ & $\mathrm{~N}-\mathrm{CH}_{3}$ in betaine & $\uparrow$ & $\uparrow$ \\
\hline approximately $3.5-4.5$ & $\mathrm{CH}_{1}$ in glucose and amino acids & $\downarrow$ & - \\
\hline $3.90-3.94$ & $\mathrm{CH}_{2}$ in betaine & $\uparrow$ & $\uparrow$ \\
\hline $4 \cdot 06-4 \cdot 10$ & $\mathrm{~N}-\mathrm{CH}_{2}$ in creatinine & - & $\downarrow$ \\
\hline $5 \cdot 69-5 \cdot 81$ & $\mathrm{NH}_{2}$ in urea & - & $\downarrow$ \\
\hline $7 \cdot 54$ & $\mathrm{CH}_{3} / \mathrm{CH}_{5}$ in hippurate & - & $\uparrow$ \\
\hline $7 \cdot 83$ & $\mathrm{CH}_{2} / \mathrm{CH}_{6}$ in hippurate & - & $\uparrow$ \\
\hline
\end{tabular}

ppm, parts per million.

${ }^{*}$ For details of procedures and diets, see p. 956 and Table 1.

†Based on Lindon et al. (1999) and Griffin et al. (2004).

$¥$ The symbols $\uparrow$ and $\downarrow$ indicate higher and lower concentrations in WGD samples compared with

NWD samples, respectively; - indicates no effect of diet.

contrasting dietary fibre characteristics (Bach Knudsen et al. 2005) and phytochemicals (Bach Knudsen et al. 2003; Linko et al. 2006) and where we, with conventional approaches, have identified marked differences in the plasma profiles of mammalian lignans, alkylresorcinols and SCFA but not in the levels of glucose, lactate and insulin (Bach Knudsen et al. 2003; Linko et al. 2006). Principal component analysis on spectra acquired on both plasma and urine samples revealed a clear separation of WGD and NWD samples (Figs 1 and 3), implying a significant effect on the metabolite plasma and urine profile of the two diets. In order to investigate the differences in the plasma metabolite profile of WGD and NWD plasma samples, PLS-DA, which is a supervised method, was performed on spectra obtained with WGD and NWD plasma samples (Fig. 2(A,B)). The regression coefficients revealed that PLS-DA could discriminate between WGD and NWD plasma samples mainly because of increases in spectral intensities of regions around $3.25 \mathrm{ppm}$ and around $1.20-1.30 \mathrm{ppm}$ in WGD plasma samples compared with NWD plasma samples; $3.25 \mathrm{ppm}$ corresponds to the chemical shift value reported for different $\mathrm{N}\left(\mathrm{CH}_{3}\right)_{3}$ groups (Lindon et al. 1999), and to investigate if this response should be ascribed to betaine, spiking of plasma with betaine was investigated, which confirmed that betaine has a resonance at $3.25 \mathrm{ppm}$ (Table 3). Accordingly, it appears that the spectral difference

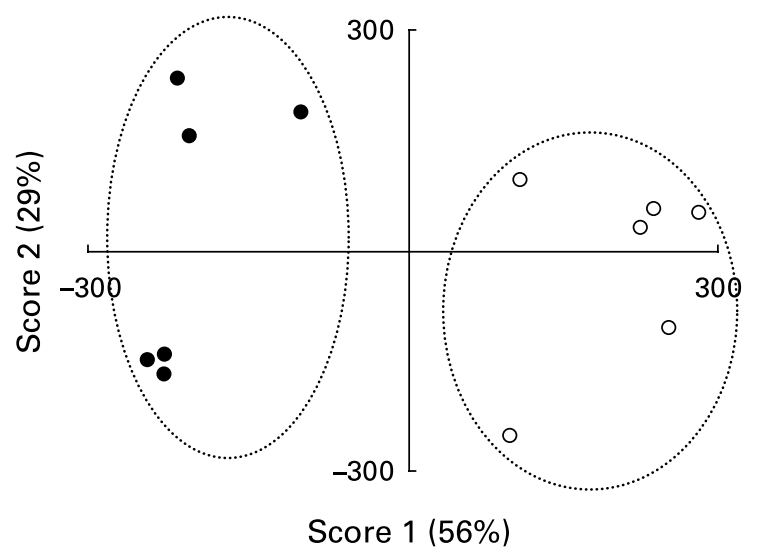

Fig. 3. Principal component analysis score plot showing the two first principal components for non-wholegrain diet $(\bullet)$ and wholegrain diet $(O)$ urine sample groups. For details of procedures, see p. 956. at $3.25 \mathrm{ppm}$ between the two diets should be ascribed to a higher level of betaine in WGD plasma compared with NWD plasma. This was confirmed by LC-MS analyses of the plasma samples, which verified a significantly higher content of betaine in WGD samples compared with NWD samples. Moreover, spiking of plasma with lignans (enterolactone) and alkylresorcinol (C15:0) were also scrutinized, which revealed that the protons of the resorcinol part give rise to a resonance at $3.22 \mathrm{ppm}$, which is relatively close to the main difference observed at $3.25 \mathrm{ppm}$. Because of the fact that resonances from the alkyl chain (approximately $1.3 \mathrm{ppm}$ ) were also observed upon spiking with alkylresorcinol (Table 3), and that this resonance also was found to play a role

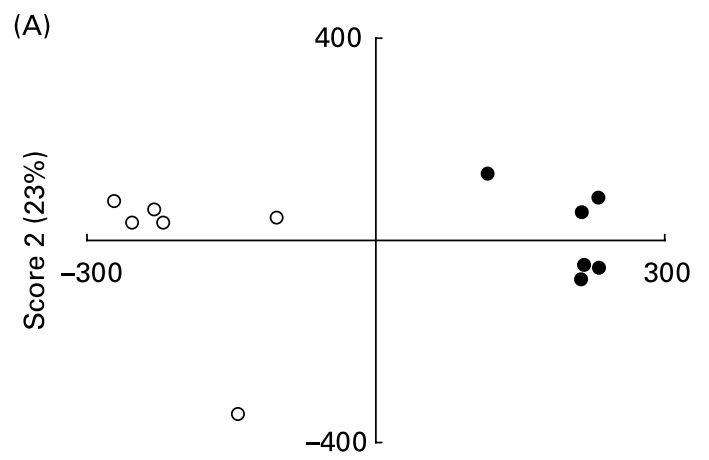

Score $1(56 \%)$

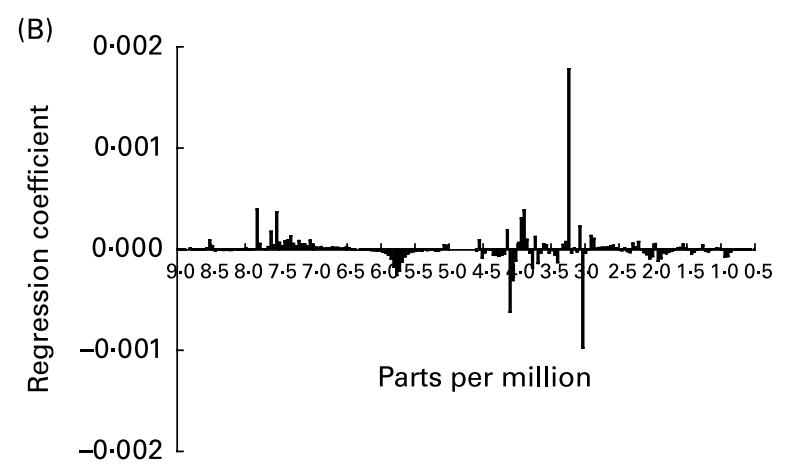

Fig. 4. (A), Partial least squares regression discriminant analysis (PLS-DA) scores plot from analysis of NMR spectra obtained on non-wholegrain diet $(\bullet)$ and wholegrain diet urine samples $(O)$. For details of procedures, see p. 956. (B), The regression coefficients of the PLS-DA shown in (A). 
Table 3. Results from spiking of plasma with various compounds

\begin{tabular}{ll}
\hline Compound & Additional resonances (ppm) \\
\hline Glycerophosphorylcholine & $4 \cdot 15,3 \cdot 62,3 \cdot 20$ \\
Betaine & $3 \cdot 9,3 \cdot 25$ \\
Enterolactone & $3 \cdot 56$ \\
Alkylresorcinol & $0 \cdot 9,1 \cdot 3,3.22$ \\
\hline
\end{tabular}

in the discrimination of the two diets (Fig. 2(B)), it cannot be completely excluded that alkylresorcinol also contributes to the main difference at $3.25 \mathrm{ppm}$. However, taking into consideration that plasma alkylresorcinol concentrations are reported to be in the nanomolar range (Linko et al. 2006), which most probably is below the limit of NMR detection (Nicholson \& Wilson, 1989), and about 1000 times lower than the plasma concentration of betaine found in the present study, it seems most likely the main difference at $3.25 \mathrm{ppm}$ primarily should be ascribed to betaine. Previous studies have shown that dietary betaine is absorbed and causes increases in serum concentrations (Frontiera et al. 1994; McGregor et al. 2002; Schwab et al. 2002; Schwahn et al. 2003), which supports the present findings of betaine absorption. Betaine has three reactive methyl groups, and works as a methyl donor in many biochemical pathways and participates in the methionine cycle (Anon, 2003). Insufficient dietary intake of methyl groups leads to hypomethylation, which may contribute to various diseases, including coronary, cerebral, hepatic and vascular diseases (Craig, 2004). In addition, betaine also has other physiological functions, is suggested to protect against protein denaturation and has been termed a 'chemical chaperone' (Caldas et al. 1999), and it helps maintain cell volume under osmotic stress (Craig, 2004). Several positive effects of betaine have been reported, as betaine may protect internal organs (Caldas et al. 1999) and improve vascular risk factors (Borsook \& Borsook, 1951; Schwab et al. 2002; Olthof et al. 2003; Steenge et al. 2003). Moreover, it has been demonstrated that betaine supplementation improved athletic performance (Armstrong et al. 2003). The present study is the first to report that a wholegrain diet affects serum betaine levels. In view of the physiological significance of betaine, the present findings must be considered extremely important. Further studies are needed to elucidate the precise role of betaine in promoting health.

Urine samples were also analysed to elucidate the biochemical effects of the two diets. Analysis of the regression coefficients revealed that PLS-DA could discriminate between WGD and NWD urine samples because of increases in spectral intensities of betaine and hippurate, and decreases in spectral intensities of creatinine and urea and in WGD urine samples compared with NWD samples (Table 2). The lower content of creatinine in WGD urine samples compared with NWD urine samples was verified by LC-MS analyses. Possibly the lower creatinine excretion in WGD samples is an indicator of alterations in protein turnover and metabolism in general. However, the reverse relationship between betaine concentrations in plasma and urinary creatinine excretion in WGD samples may also be related. Even though several studies have investigated the various effects of betaine (Borsook \& Borsook, 1951;
Keshavarz \& Fuller, 1971; Burg, 1995; Matthews et al. 2001; McGregor et al. 2002; Schwab et al. 2002; Armstrong et al. 2003; Kim et al. 2003; Ozturk et al. 2003; Schwahn et al. 2003; Slow et al. 2004; Wray-Cahen et al. 2004), to the authors' knowledge, a latent relationship between plasma betaine content and urinary excretion of creatinine has not been elucidated, but might be a result of three different mechanisms. First, betaine is a well-known osmoregulatory biomolecule (Craig, 2004), and therefore might simply reduce creatinine clearance to the urine. Second, another explanation might be ascribed to the fact that methyl donation is required in the biosynthesis of creatine, and creatinine is the metabolic end-product of creatine catabolism. Accordingly, an interaction between plasma betaine content and creatinine excretion is likely, potentially through homocysteine metabolism. A higher content of muscle creatine upon betaine supplementation has been demonstrated in chicks (Chamruspollert et al. 2002). However, it is not understood why a betaine-induced increase in muscle creatine should reduce the urinary excretion of creatinine. Third, it has been hypothesized that biomolecules with an electrophilic methyl group, e.g. as found in betaine, may represent an important control system for in vivo redox balance (Ghyczy \& Boros, 2001), and it has been shown that betaine treatment decreases oxidative stress in the liver of ethanol-treated guinea pigs (Balkan et al. 2004), and in children with increased vulnerability to oxidative stress as a consequence of autism (James et al. 2004). Considering that betaine improves the redox balance in the rye-fed pigs, resulting in decreased oxidative stress, this might be consistent with the lower urine creatinine excretion in these animals, as oxidative stress has been reported to be inversely correlated to creatinine clearance (Antolini et al. 2004). No matter whether the content of plasma betaine and the level of urine creatinine is independent or a result of some of the hypotheses mentioned earlier, these aspects need to be studied further to exploit the biological consequences of the two diets further.

In conclusion, using NMR-based metabonomics as an explorative approach on the pig as a human model, the present study disclosed metabolic effects of a wholegrain diet on the content of betaine in plasma and excretion of betaine and creatinine, which may contribute to the health benefits of a high dietary intake of wholegrain. Further studies emphasizing the beneficial role of betaine and its potential connection with creatinine excretion in the health-promoting effect of wholegrain cereals are needed.

\section{Acknowledgements}

We thank Winnie Østergaard Thomsen for technical assistance, and Henry Jørgensen and Ricarda Greuel Engberg for help with performing the surgery. Moreover, Danisco Animal Nutrition, Naantali, Finland, is acknowledged for performing the betaine analyses of the feed.

This work was supported by the Nordic Industrial Fund, the Danish Agricultural and Veterinary Research Council, the Danish Technology and Production Research Council (project no. 274-05-339), Cerealia, Sweden; Wasabröd, Sweden; Vaasan \& Vaasan, Finland, Fazer Oululainen, Finland, 
the Danish Biotechnological Instrument Centre and Carlsbergfondet, Denmark.

\section{References}

Anderson JW, Hanna TJ, Peng X \& Kryscio RJ (2000) Whole grain foods and heart disease risk. J Am Coll Nutr 19, S291-S299. Anon (2003) Betaine Monograph. Altern Med Rev 8, 193-196.

Antolini F, Valente F, Ricciardi D \& Fagugli RM (2004) Normalization of oxidative stress parameters after kidney transplants is secondary to full recovery of renal function. Clin Nephrol 62, $131-137$.

Armstrong LE, Roti MW, Hatch HL, et al. (2003) Rehydration with fluids containing betaine: running performance and metabolism in a $31 \mathrm{C}$ environment. Med Sci Sports Exerc 35, S311 Abstr.

Bach Knudsen KE, Serena A, Kjær AKB, Jørgensen H \& Engberg R (2005) Rye bread enhances the production and plasma concentration of butyrate but not the plasma concentrations of glucose and insulin in pigs. $J$ Nutr 135, 1696-1704.

Bach Knudsen KE, Serena A, Kjær AKB, Tetens I, Heinonen S-M, Nurmi T \& Adlercreutz H (2003) Rye bread in the diet of pigs enhances the formation of enterolactone and increases its levels in plasma, urine and feces. J Nutr 133, 1368-1375.

Balkan J, Öztezcan S, Küçük M, Çevikbaş U, Koçak-Toker N \& Uysal M (2004) The effect of betaine treatment on triglyceride levels and antioxidative stress in the liver of ethanol-treated guinea pigs. Exp Toxicol Pathol 55, 505-509.

Beckonert O, Bollard ME, Ebbels TMD, Keun HC, Antii H, Holmes E, Lindon JC \& Nicholson JK (2003) NMR-based metabonomic toxicity classification: hierarchical cluster analysis and knearest-neighbour approaches. Anal Chim Acta 490, 3-15.

Beckwith-Hall BM, Holmes E, Lindon JC, Gounarides J, Vickers A, Shapiro M \& Nicholson JK (2002) NMR-based metabonomic studies on the biochemical effects of commonly used drug carrier vehicles in the rat. Chem Res Toxicol 15, 1136-1141.

Borsook ME \& Borsook H (1951) Treatment of cardiac compensation with betaine and glycosamine. Ann West Med Surg 5, 830-855.

Burg M (1995) Molecular basis of osmotic regulation. Am J Physiol 268, F983-F996.

Caldas T, Demont-Caulet N, Ghazi A \& Richarme G (1999) Thermoprotection by glycine betaine and choline. Microbiology 145, 2543-2548.

Chamruspollert M, Pesti GM \& Bakalli RI (2002) The influence of labile dietary methyl donors on the arginine requirement of young broiler chicks. Poult Sci 81, 1142-1148.

Coen M, Lenz EM, Nicholson JK, Wilson ID, Pognan F \& Lindon JC (2003) An integrated metabonomic investigation of acetaminophen toxicity in the mouse using NMR spectroscopy. Chem Res Toxicol 16, 295-303.

Craig S (2004) Betaine in human nutrition. Am J Clin Nutr 80, $539-549$

Ebbels T, Keun H, Beckonert O, Antti H, Bollard M, Holmes E, Lindon JC \& Nicholson JK (2003) Toxicity classification from metabonomic data using a density superposition approach: 'CLOUDS'. Anal Chim Acta 490, 109-122.

Frontiera MS, Stabler SP, Kolhouse JF \& Allen RH (1994) Regulation of methionine metabolism: effects of nitrous oxide and excess dietary methionine. J Nutr Biochem 5, 28-38.

Fung TT, Hu FB, Pereira MA, Liu S, Stampfer MJ, Colditz GA \& Willett WC (2002) Whole-grain intake and the risk of type 2 diabetes: a prospective study in men. Am J Clin. Nutr 76, 535-540.

Ghyczy M \& Boros M (2001) Electrophilic methyl groups present in the diet ameliorate pathological states induced by reductive and oxidative stress: a hypothesis. Br J Nutr 85, 409-414.

Griffin JL, Anthony DC, Campbell SJ, Gauldie J, Pitossi F, Styles P \& Sibson NR (2004) Study of cytokine induced neuropathology by high resolution proton NMR spectroscopy of rat urine. FEBS Lett 568, 49-54.

Holmes E, Nicholls AW, Lindon JC, et al. (1998) Development of a model for classification of toxin-induced lesions using ${ }^{1} \mathrm{H}$ NMR spectroscopy of urine combined with pattern recognition. NMR Biomed 11, 235-244.

James SJ, Cutler P, Melnyk S, Jernigan S, Janak L, Gaylor DW \& Neubrander JA (2004) Metabolic biomarkers of increased oxidative stress and impaired methylation capacity in children with autism. Am J Clin Nutr 80, 1611-1617.

Kamal-Eldin A, Pouru A, Eliasson C \& Åman P (2000) Alkylresorcinols as antioxidants: hydrogen donation and peroxyl radicalscavenging effects. J Sci Food Agric 81, 353-356.

Keshavarz K \& Fuller HI (1971) Relationship of arginine and methionine in the nutrition of the chick and the significance of creatine biosynthesis in their interaction. J Nutr 101, 217-222.

Keun HC, Ebbels TMD, Antti H, et al. (2002) Analytical reproducibility in ${ }^{1} \mathrm{H}$ NMR-based metabonomic urinalysis. Chem Res Toxicol 15, 1380-1386.

Kim SK, Choi KH \& Kim YC (2003) Effect of acute betaine administration on hepatic metabolism of S-amino acids in rats and mice. Biochem Pharmacol 65, 1565-1574.

Lenz EM, Wilson ID, Timbrell JA \& Nicholson JK (2000) A ${ }^{1} \mathrm{H}$ NMR spectroscopic study of the biochemical effects of ifosfamide in the rat: evaluation of potential biomarkers. Biomarkers 5, 424-435.

Levi F, Pasche C, Lucchini F, Chatenoud L, Jacobs DR Jr \& La Vecchia C (2000) Refined and whole grain cereals and the risk of oral, oesophageal and laryngeal cancer. Eur J Clin Nutr 54, 487-489.

Lindon JC, Nicholson JK \& Everett JR (1999) NMR spectroscopy of biofluids. Ann Rep NMR Spectrom 38, 1-88.

Linko AM, Ross AB, Kamal-Eldin A, Serena A, Kjar AKB, Jørgensen H, Peñalvo JL, Adlercreutz H, Åman P \& Back Knudsen KE (2006) Kinetics of the appearance of cereal alkylresorcinols in pig plasma. Br J Nutr 95, 282-287.

McGregor DO, Dellow WJ, Robson RA, Lever M, George PM \& Chambers ST (2002) Betaine supplementation decreases postmethionine hyperhomocysteinemia in chronic renal failure. Kidney Int 61, 1040-1046.

McKeown NM, Meigs JB, Liu S, Wilson PW \& Jacques PF (2002) Whole-grain intake is favorably associated with metabolic risk factors for type 2 diabetes and cardiovascular disease in the Framingham Offspring Study. Am J Clin Nutr 76, 390-398.

Martens H \& Dardenne P (1998) Validation and verification of regression in small data sets. Chemometrics Intell Lab Syst 44, 99-121.

Matthews JO, Southern LL, Higbie AD, Persica MA \& Bidner TD (2001) Effects of betaine on growth, carcass characteristics, pork quality, and plasma metabolites of finishing pigs. J Anim Sci 79, $722-728$.

Miller ER \& Ullrey DE (1987) The pig as a model for human nutrition. Annu Rev Nutr 7, 361-382.

Nicholson JK, Buckingham MJ \& Sadler PJ (1983) High resolution ${ }^{1} \mathrm{H}$ n.m.r. studies of vertebrate blood and plasma. Biochem $\mathrm{J} \mathbf{2 1 1}$, 605-615.

Nicholson JK \& Wilson ID (1989) High resolution proton nuclear magnetic resonance spectroscopy of biological fluids. Progr NMR Spectrom 21, 449-501.

Olthof MR, van Vliet T, Boelsma E \& Verhoef P (2003) Low dose betaine supplementation leads to immediate and long term lowering of plasma homocysteine in healthy men and women. J Nutr 133, 4135-4138.

Ozturk F, Ucar M, Ozturk IC, Vardi N \& Batcioglu K (2003) Carbon tetrachloride-induced nephrotoxicity and protective effect of betaine in Sprague-Dawley rats. Urology 62, 353-356.

Pereira MA, Jacobs DR, Pins JJ Jr, Raatz SK, Gross MD, Slavin JL \& Seaquist ER (2002) Effect of whole grains on insulin sensitivity in overweight hyperinsulinemic adults. Am J Clin Nutr 75, 848-855. 
Saarinen MT, Kettunen H, Pulliainen K, Peuranen S, Tiihonen K \& Remus J (2001) A novel method to analyze betaine in chicken liver: effect of dietary betaine and choline supplementation on the hepatic betaine concentration in broiler chicks. J Agric Food Chem 49, 559-563.

Schwab U, Törrönen A, Toppinen L, Alfthan G, Saarinen M, Aro A \& Uusitupa M (2002) Betaine supplementation decreases plasma homocysteine concentrations but does not affect body weight, body composition, or resting energy expenditure in human subjects. Am J Clin Nutr 76, 961-967.

Schwahn BC, Hafner D, Hohlfeld T, Balkenhol N, Laryea MD \& Wendel U (2003) Pharmacokinetics of oral betaine in healthy subjects and patients with homocystinuria. Br J Clin Pharmacol 55, 6-13.

Slavin JL, Jacobs D, Marquart L \& Wiemer K (2001) The role of whole grains in disease prevention. J Am Diet Assoc 101, 780-785.

Slavin JL, Martini M, Jacobs DR Jr \& Marquart L (1999) Plausible mechanisms for the protectiveness of whole grains. Am J Clin Nutr 70, 459S-486S.

Slow S, Lever M, Lee MB, George PM \& Chambers ST (2004) Betaine analogues alter homocysteine metabolism in rats. Int J Biochem Cell Biol 36, 870-880.

Solanky KS, Bailey NJC, Beckwith-Hall BM, Davis A, Bingham S, Holmes E, Nicholson JK \& Cassidy A (2003b) Application of biofluid ${ }^{1} \mathrm{H}$ nuclear magnetic resonance-based metabonomic techniques for the analysis of the biochemical effects of dietary isoflavones on human plasma profile. Anal Biochem 323, $197-204$.

Solanky KS, Bailey NJC, Holmes E, Lindon JC, Davis AL, Mulder TPJ, Van Duynhoven JPM \& Nicholson JK (2003a) NMR-based metabonomic studies on the biochemical effects of epicatechin in the rat. J Agric Food Chem 51, 4139-4145.

Steenge GR, Verhoef P \& Katan MB (2003) Betaine supplementation lowers plasma homocysteine in healthy men and women. J Nutr 133, $1291-1295$.

Truswell AS (2002) Cereal grains and coronary heart disease. Eur J Clin Nutr 56, 1-14.

Waters NJ, Holmes E, Williams A, Waterfield CJ, Farrant RD \& Nicholson JK (2001) NMR and pattern recognition studies on the time-related metabolic effects of $\alpha$-naphthylisothiocyanate on liver, urine, and plasma in the rat: an integrative metabonomic approach. Chem Res Toxicol 14, 1401-1412.

Wray-Cahen D, Fernández-Fígares I, Virtanen E, Steele N \& Caperna TJ (2004) Betaine improves growth, but does not induce whole body or hepatic oxidation in swine (Sus scrofa domestica). Comp Biochem Physiol A Mol Integr Physiol 137, $131-140$. 